\title{
Heat and Water Vapour Transfer Trough the Envelope of a Cold Chamber
}

\author{
Clito Afonso \\ Department of Mechanical Engineering, Faculty of Engineering of Porto University, Porto, R. Dr. Roberto Frias, Porto 4200-465, \\ Portugal
}

\begin{abstract}
The diffusion of water vapour in the atmospheric air through the elements of the envelope of a cold storage room, caused by the pressure gradient between the external and internal environment is inevitable in most situations. In fact, if the conditions in the interior of an envelope element are such as to enable the vapour freezing of the migrant water, the increase in volume from the formation of ice will causes the deformation of this element with very serious consequences, which can go up to its partial or total destruction. In this scenario, readily note the importance of vapour barriers associated with a properly designed insulation, tend to not only reduce the amount of water diffused, but also prevent the achievement of the conditions for freeze inside the engaging elements. The purpose of this work is to formulate the procedure for design of vapour barriers connected with the design of optimized thermal insulation, and then apply it to a cold chamber located in Portugal. Vapour barriers and the procedure for its design are both mandatory. The required thickness of the vapour barrier is relatively small, and the most appropriate insolation (maintaining the optimal thickness) is the black cork agglomerate.
\end{abstract}

Key words: Ice formation, Fick's Law, vapour barriers, cold chamber.

\section{Introduction}

The IIR [1] estimates that there are in operation throughout the world, of about 3,000 million refrigeration systems, which represents about $17 \%$ of the electricity used. So, besides the improvement of all equipment's of these systems in order to achieve better efficiencies, there has to be special attention in the envelope of the cold rooms. Therein the heat and water vapour transfer occurs between the inside and the outside environment.

The mechanism underlying strength to the vapour diffusion through the successive layers of materials forming the envelope element is the gradient of partial pressures of the vapour between the outside and inside air, while the temperature gradient causes the energy transfer. The interdependence of temperature and pressure studied in thermodynamics [2], allow to state that the regions of higher temperatures are also of higher pressures. Therefore, given the interdependence

Corresponding author: Clito Afonso, Ph.D., professor, research areas/interests: applied thermodynamics, environment. between pressure and temperature, mass and heat transfer processes are intrinsically related and must be analysed simultaneously

The way to avoid/minimize the vapour condensation inside the structure of the envelope, is the placement of vapour barriers in the warmer side of the insulation. There are two types vapour barrier for their ability to prevent vapour migration: total limiting barriers and partial vapour migration. The former is of metallic or plastic type, whereas the latter is in essence of the bituminous type. In this work, only the latter will be analysed.

The aim of this study is to calculate the vapour mass flowrate and heat transfer through the successive elements of the envelope of a cold chamber located in Portugal. Then, with the results obtained, if there is vapour condensation inside the envelope (with all the inherent risks), the appropriate vapour barrier will be analysed and chosen.

\section{Theoretical Formulation}

The study of moisture transfer can be done from the 
Navier-Stokes equation, where it follows the Fick's law, which is the basis for mathematical models of thermodiffusion [3]:

$$
\overrightarrow{\mathrm{g}}=-\mathrm{k}_{\mathrm{dif}} \cdot \operatorname{grad}(\mathrm{c} \rho)
$$

From this equation it is possible to deduce the general equation of vapour diffusion through porous materials, known as Fick's law:

$$
\frac{\partial(c \rho)}{\partial \tau}=\operatorname{div}\left[\mathrm{k}_{\mathrm{dif}} \cdot \operatorname{grad}(\mathrm{c} \rho)\right]+I
$$

Considering a typical situation, which is a homogeneous non-hygroscopic wall with flat and parallel internal surfaces and without internal flow production, the concentration can be obtained from the Eq. (3):

$$
c=\frac{m_{d}}{m_{d}+m_{D}}=\frac{\rho_{d}}{\rho_{d}+\rho_{D}}=\frac{\rho_{d}}{\rho}
$$

By making use of the Clayperon equation [4], for steam, it follows that:

$$
p v_{d}=\frac{p}{\rho_{d}}=\mathrm{ZRT}
$$

From Eqs. (3) and (4) it follows that:

$$
c \rho=\frac{p}{R} \frac{1}{Z T}
$$

So, Eq. (2) can then be rewritten as:

$$
\frac{\partial\left(\frac{p}{Z T}\right)}{\partial \tau}=\operatorname{div}\left[\mathrm{k}_{\text {dif }} \cdot \operatorname{grad}\left(\frac{p}{Z T}\right)\right]
$$

Assuming steady state with a constant diffusion coefficient, which is acceptable in most cases of vapor diffusion through the elements of the envelope, Eq. (6) is reduced to:

$$
\nabla^{2}\left(\frac{p}{Z T}\right)=0
$$

On the other hand, if the flow through one envelope element is unidirectional, which is an acceptable simplification for the current zones of the element, and assuming that the steam has a perfect gas behaviour $(Z=1)$ it is finally obtained:

$$
\frac{\partial^{2}\left(\frac{p}{T}\right)}{\partial x^{2}}=0
$$

To better understand the applicability of these equations, it is necessary to consider the extreme case of vapour diffusion through a wall in isothermal regime. If the wall is at " $\mathrm{T}$ " temperature, there is a thickness "e", and it is subject to an inner partial pressure " $p_{i}$ " and external " $p_{e}$ ". The integration of Eq. (8) determines the distribution law of the partial pressure of the vapour inside the wall. This law is translated by Eq. (9) and is illustrated in Fig. 1a.

$$
p_{(x)}=\left(p_{e}-p_{i}\right) \frac{x}{e}+p_{i}
$$

Therefore, in permanent and monodirectional regime, the pressure evolves linearly inside a solid component of the envelope. Note that the saturation pressure of the migrant steam is constant because the temperature does not vary, and has always been considered superior to the partial vapour pressure over the element, which does not always happen.

From this analysis, the Fick's law for porous materials can be written as Eq. (10):

$$
\dot{g}=-\Pi \frac{d p}{d x}
$$

Fig. 1b illustrates this law, which is valid for vapour diffusion conditions stated above.

However, it is not the real equality between the inside and outside temperatures of the envelope, because it is subjected to temperature gradients. In this case, the saturation pressure varies from point to point through the thickness of the element. So there are two situations:

- If the line of partial pressures $\left(\mathrm{p}_{\mathrm{e}}-\mathrm{p}_{\mathrm{i}}\right)$ does not intercept the saturation pressure curve (as shown in Fig. 2a), there will be no condensation in the interior of the element.

- If, however, the two curves intersect (Fig. 2b), condensation will take place.

Making use of Fick's law [5] it can be determined the amount of water that deposits inside an envelope 


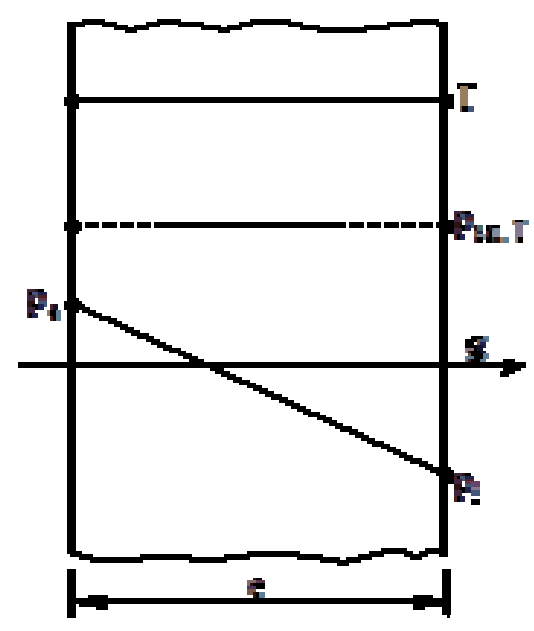

(a)

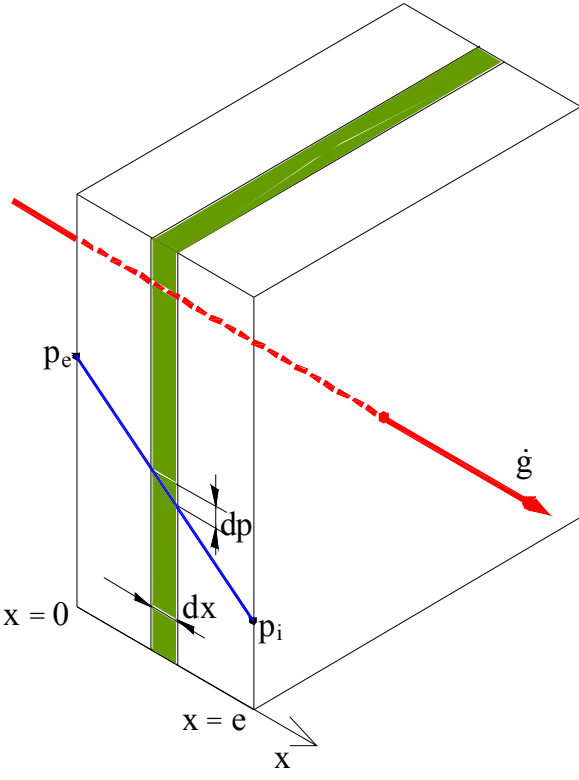

(b)

Fig. 1 (a) Isothermal vapor diffusion in steady state; (b) Linear variation of pressure in the interior of a solid element.

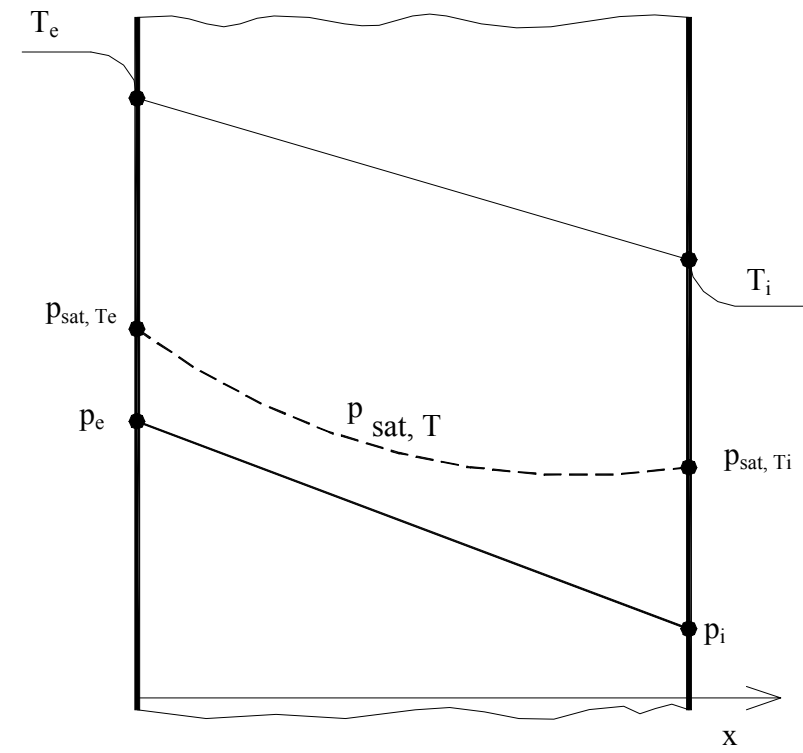

(a)

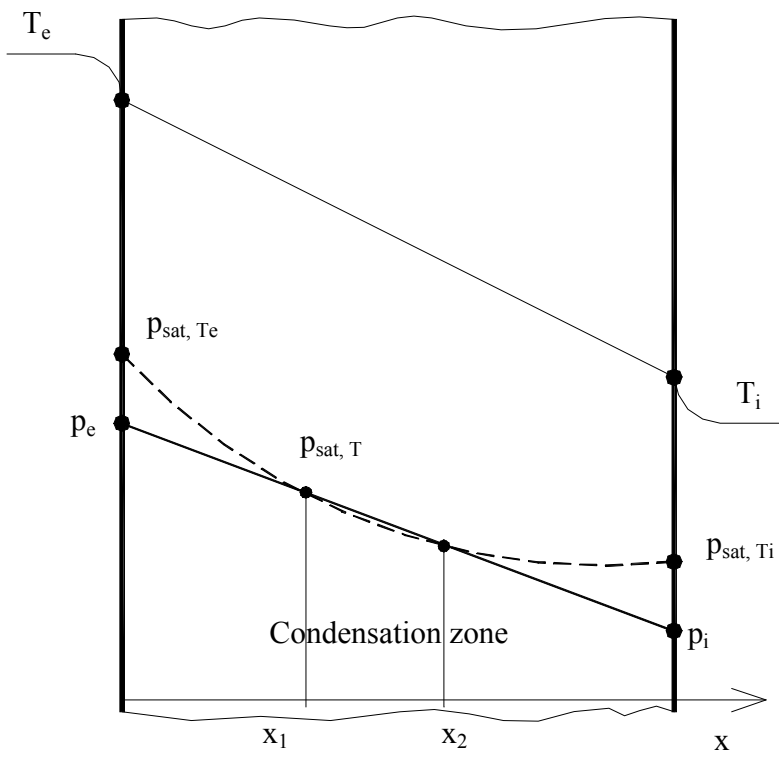

(b)

Fig. 2 Vapour diffusion without/-with condensation in an element subject to a temperature gradient.

element. Given that the condensate flow is equal to the difference between the input and output flows on the surfaces $\mathrm{x}_{1}$ and $\mathrm{x}_{2}$ (see Fig. 2b), it is obtained:

$$
\dot{g}=\Pi\left[\left(\frac{d p}{d x}\right)_{x=x_{1}}-\left(\frac{d p}{d x}\right)_{x=x_{2}}\right]
$$

Generally, the envelope elements of refrigeration chambers are not homogeneous, but rather composed of layers of materials that can be considered homogeneous, each with its conductivity and permeability. Thus, if $\mathrm{e}_{1}, \mathrm{e}_{2}, \ldots, \mathrm{e}_{\mathrm{n}}$ and $\Pi_{1}, \Pi_{2}, \ldots, \Pi_{\mathrm{n}}$ are respectively the thicknesses and permeability's of the different layers, the diffused steam flow in steady state is obtained by integrating Eq. (10) and will be equal to: 


$$
\begin{aligned}
& \dot{g}=\Pi_{1} \frac{p_{e}-p_{2}}{e_{1}}=\Pi_{2} \frac{p_{3}-p_{2}}{e_{2}}=\ldots \\
& =\prod_{\mathrm{n}} \frac{p_{n}-p_{n-1}}{e_{n}}=\sum_{i=1}^{n}\left(\Pi \frac{\Delta p}{e}\right)_{i}
\end{aligned}
$$

Defining vapour diffusion resistance of a given material "I", the relationship between the thickness and permeability is:

$$
R_{v, i}=\frac{e_{i}}{\Pi_{i}}
$$

So, the total resistance of the element envelope to vapour diffusion can then be defined as:

$$
R_{v, e q}=\sum_{i=1}^{n} R_{v, i}=\sum_{i=1}^{n} \frac{e_{i}}{\Pi_{i}}
$$

And vapour flow per unit area is determined by:

$$
\dot{g}=\frac{\Delta p}{R_{v, e q}}=\frac{p_{e}-p_{i}}{R_{v, e q}}
$$

As can be seen from Fig. 2, the saturation pressure of the water vapour varies inside each element of the envelope as a function of the temperature in it. Thus, priority to any calculation, it is necessary to know in each section of the element what the prevailing temperature is. This can be done through the heat transfer analysis of the wall, which is composed of several elements, as shown in Fig. 3.

The heat transfer trough the wall is given by Refs. $[6,7]$ :

$$
\dot{q}=\frac{T_{\operatorname{Pr} o j, E x t}-T_{\operatorname{Pr} o j, I n t}}{R_{t, E x t-I n t}}
$$

where the total thermic resistance between the outside and inside environment is:

$$
R_{t, E x t-I n t}=\frac{1}{\alpha_{E x t}}+\sum_{i=1}^{n}\left(\frac{e}{\lambda}\right)_{i}+\frac{1}{\alpha_{I n t}}
$$

So, the temperature in each section $(\mathrm{x})$ is:

$$
T_{x}=T_{\operatorname{Pr} o j, E x t}-\dot{q} \cdot R_{t, E x t-x}
$$

where:

$$
R_{t, E x t-x}=\frac{1}{\alpha_{E x t}}+\sum_{i=1}^{x}\left(\frac{e}{\lambda}\right)_{i}
$$

The knowledge of the values of the temperatures at

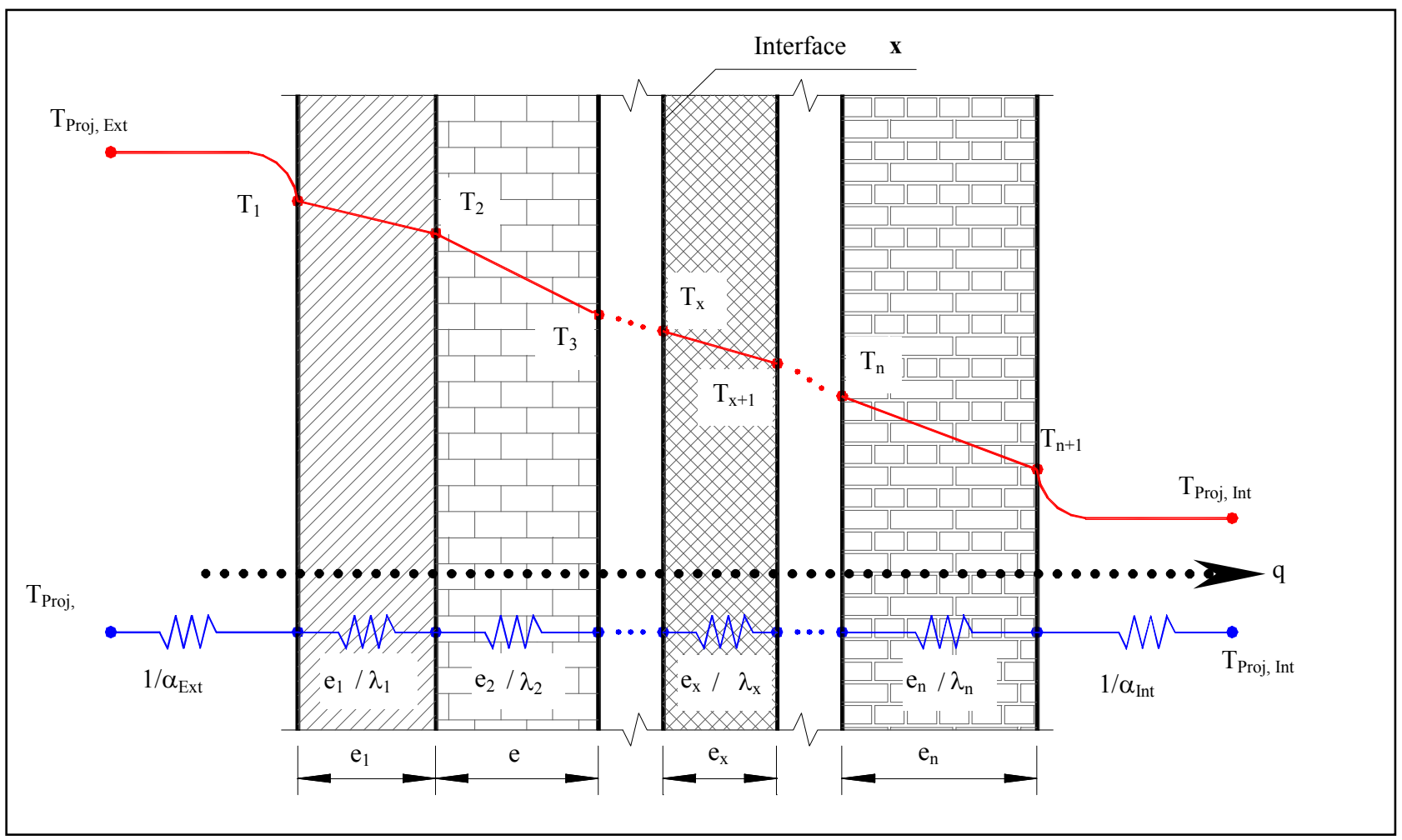

Fig. 3 Heat transfer in a composite wall. 


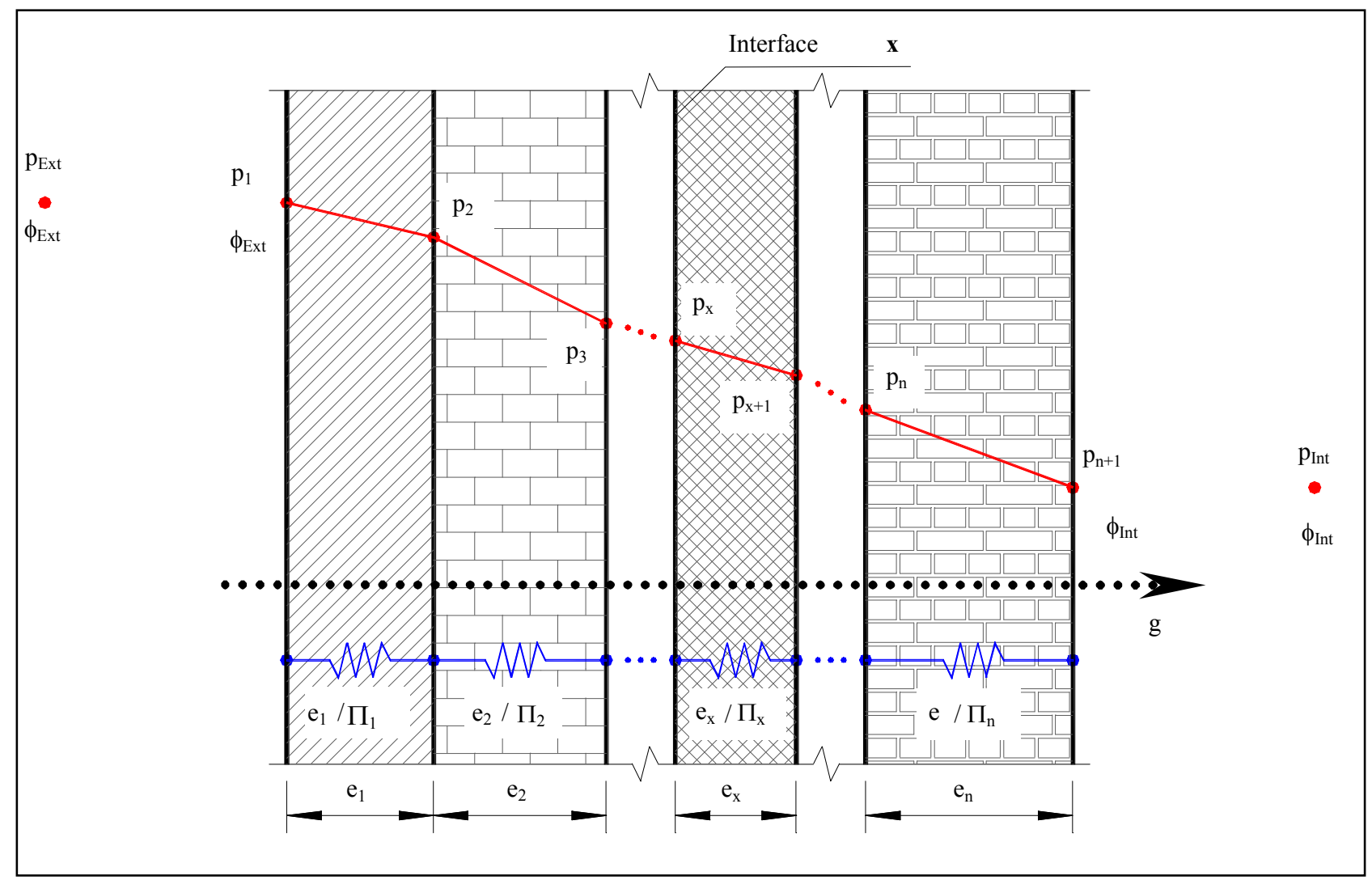

Fig. 4 Vapour diffusion in a composite element.

the interfaces allow the determination the partial pressure of vapour, which is used in the study of vapour diffusion through the element, as in Fig. 4.

So, the partial pressure of vapour at the interface ' $x$ ' $\left(p_{x}\right)$, is similar to that indicated for the temperature (Eq. (18)) with the expression:

$$
p_{x}=p_{E x t}-\dot{g} \cdot R_{v, E x t-x}
$$

where:

$$
R_{v, E x t-x}=\sum_{i=1}^{x} R_{v, i}=\sum_{i=1}^{x}\left(\frac{e}{\Pi}\right)_{i}
$$

Despite the implementation of good vapour barriers, it is virtually impossible to prevent small quantities of water vapour entering the warm side of the insulation (unless, as stated above, with metal or plastic barriers). It is therefore necessary that the water vapour that passes through the vapour barrier can be spread over the insulation and out of the cold side into the cooling chamber, which eventually will condense in the evaporators. Thus, it is important that the coating of the internal elements (inside the chamber) is very permeable because if it is too tight, the sealing of the vapour barrier must be great enough, in order to avoid, in any event, that more water vapour enters to the isolation than what goes into the cooling chamber.

With the calculated partial pressures of the vapour and, as said, if $p_{\mathrm{sat}, \mathrm{Tx}} \leq \mathrm{p}_{\mathrm{v}, \mathrm{Tx}}$ there is no occurrence or non-condensing a given surface. If not, it is necessary to calculate the partial pressures of the element where condensation occurs, and with them the flow of vapour migrates from the outside, and the flow of vapour reaches the interior of the cooling chamber. The difference between them is the condensed vapour flow. In Fig. 2, suppose that the condensation occurs at the interface " $x$ ". So, this vapour is in the saturated state at the surface which means that the pressures are equal: $\quad p_{v(T)}=\varphi \cdot p_{v, \text { sat }(T)}$. In this situation, the vapour flow into the element is:

$$
\dot{g}_{\text {ext }}=\frac{p_{1}-p_{x}}{R_{v, 1-x}}
$$


The vapour flow that reaches the inner surface of the refrigeration chamber is:

$$
\dot{g}_{I n t}=\frac{p_{x}-p_{n+1}}{R_{v, x-(\mathrm{n}+1)}}
$$

The difference between these vapour flows (Eqs. (22) and (23)) is the vapour that has been condensate:

$$
\dot{g}_{\text {Cond }}=\dot{g}_{E x t}-\dot{g}_{\text {Int }}
$$

\section{Application of the Methodology to Cold Chamber in Portugal}

The above methodology was tested in a cold chamber located in Portugal. Two models were analysed: one without vapour barrier (Fig. 5a) and another with vapour barrier (Fig. 5b). The wall

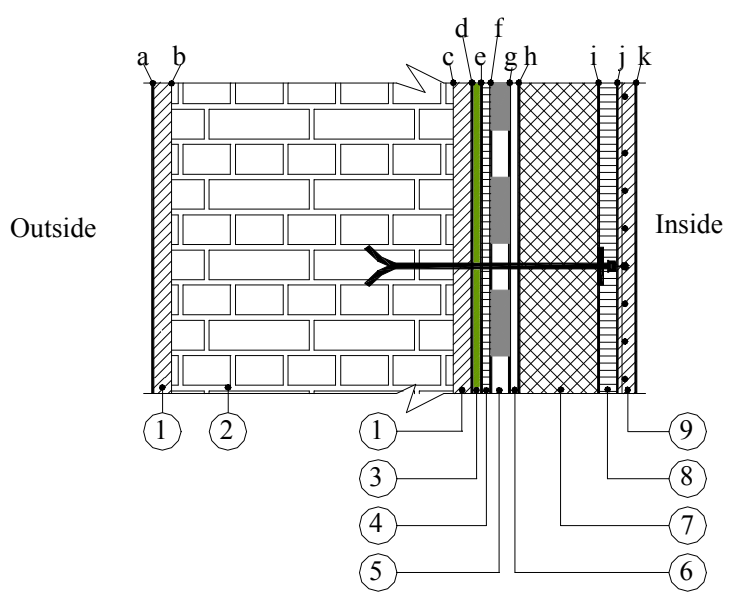

(a) structure model is diagrammed in the same figure, where it is observed of the identification of the construction materials ("1"-"9") and the interfaces between the layers of materials ("a"-"k"). The thermal and hygroscopic properties of these materials are registered in Table 1.

Models without/with vapour barrier serve the objectives of the analysis. Both models have thermal insulation with a thickness equal to the optimal thickness [2].

Simulation were done for the three most common types of thermal insulation (ERP rigid polyurethane foam; PLE-expanded polyethylene and black CRT-agglomerated cork) and limiting vapour barriers (bituminous surface-BT, aluminium foil with e $>40$ $\mu \mathrm{m}-\mathrm{AF}$ and polyethylene with $\mathrm{e}=100 \mu \mathrm{m}$-Poly).

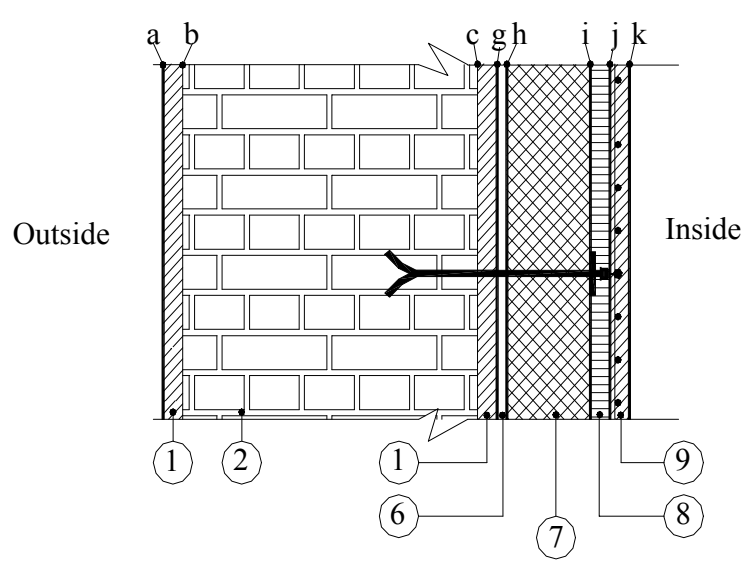

(b)

Fig. 5 (a) Without vapour barrier; (b) With vapour barrier.

Table 1 Characteristics of building materials of walls $[8,9]$.

\begin{tabular}{llll}
\hline Material & Conductibility $\lambda\left[\mathrm{W}(\mathrm{m} \cdot \mathrm{K})^{-1}\right]$ & Thickness e $[\mathrm{cm}]$ & Permeability $\Pi\left[\mathrm{g}(\mathrm{m} \cdot \mathrm{h} \cdot \mathrm{mm} \cdot \mathrm{Hg}]^{-1}\right.$ \\
\hline 1 Cement grout & 1.105 & 1.5 & $7.00 \mathrm{E}-04$ \\
2 Brick wall $(22 \mathrm{~cm})$ & 0.480 & 22.0 & $5.00 \mathrm{E}-03$ \\
3 Primary bituminous & 0.230 & 1.0 & $2.20 \mathrm{E}-03$ \\
4 Asphaltic bitumen & 0.230 & 0.5 & $2.20 \mathrm{E}-03$ \\
5 Vapour barrier & 3 different vapour barriers & & $1.00 \mathrm{E}-03$ \\
6 Asphaltic bitumen & 0.230 & 0.5 & $2.20 \mathrm{E}-03$ \\
7 Thermal insulation & 3 different vapour barriers & optimal & $5.00 \mathrm{E}-03$ \\
8 Asphaltic bitumen & 0.230 & 1.5 & $2.20 \mathrm{E}-03$ \\
9 Reinforced plastering & 1.150 & 2.0 & $6.50 \mathrm{E}-04$ \\
\hline
\end{tabular}




\section{Results}

The calculations were carried out using the models described in the previous section as demands corresponding to three different temperatures within the chamber at $-10{ }^{\circ} \mathrm{C},-20^{\circ} \mathrm{C}$ and $-30{ }^{\circ} \mathrm{C}$. Regarding the outside temperature, although there were hourly analysed the temperatures for one day of summer and winter, it was only considered here the maximum temperature in summer, $37^{\circ} \mathrm{C}$, as the critical temperature.

In all simulated models without a vapour barrier it has been found that there is a possibility of condensation (unless a limiting vapour barrier is placed). Fig. 6 shows the temperature decay along the envelope and the evolution of the saturation and partial pressure of the vapour along the wall. These results were obtained when the thermal insulation used was the expanded polyethylene (for others insulations the situation is identical).

As noted, in the interfaces " $\mathrm{i}-\mathrm{k}$ " the partial pressure of saturated vapour is below the partial pressure, indicating that there is condensation. The vapour flow that is condensed was calculated with the Eq. (24) and indicated in Table 2. The units and symbology of the quantities used are as follow: $\mathrm{T}_{\text {int }}\left[{ }^{\circ} \mathrm{C}\right]$; $\mathrm{e}_{\mathrm{opt}}[\mathrm{cm}]$; Heat flux-Q $\quad[\mathrm{W}] ; \quad$ Vapour flux-V $\quad\left[\mathrm{ng}\left(\mathrm{sm}^{2}\right)^{-1}\right]$; Condensate-Cond. [ng( $\left.\left.\mathrm{sm}^{2}\right)^{-1}\right] ; \mathrm{e}[\mathrm{m}]$.

Therefore, the constructive solution using the optimal thickness of insulation is not enough to prevent condensation inside the element, requiring the placement of a limiting vapour barrier to prevent it.

Note that in the analysed situations, it is not possible to avoid condensation using only the variation of the thickness of the thermal insulation because it would be required for unsustainable thickness values (of the order of $3 \mathrm{~m}$ in thickness).

Knowing this, the main objective of the hygroscopic analysis is sizing of the vapor barrier in order to prevent this occurrence. Following the procedure described above, the results obtained for the three types of barriers can be seen in Table 2 .

For the temperature inside the chamber equal to $-10{ }^{\circ} \mathrm{C}$ (for other analysed temperatures the relationship is identical), Fig. 7 shows the magnitude of the thickness of the vapour barriers depending on the type of insulation used. It is clear that the aluminium foil $(e>40 \quad \mathrm{~m})$ requires a substantially lower thickness when compared with the others, as would be expected due to its lower permeability.

It is possible to arrive at the same conclusion by analyzing Fig. 8, which shows the evolution of thicknesses for each of the tested vapor barriers, depending on the type of insulation and temperature within the chamber.

In Fig. 8, it is easily observed that the thinner insulation material for the three temperatures, corresponds to black cork agglomerate, whose optimum thickness is, however, superior to the other two insulating materials (Table 2).

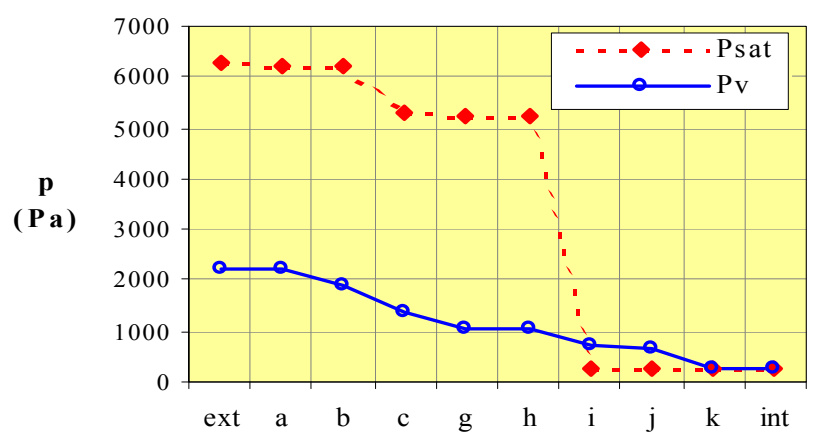

Fig. 6 Temperature evolution and vapour partial and saturation pressure through the wall. 
Table 2 Results obtained with/without vapour barrier.

\begin{tabular}{|c|c|c|c|c|c|c|c|c|c|}
\hline \multirow[t]{2}{*}{$\mathrm{T}_{\mathrm{int}}$} & \multicolumn{3}{|c|}{ Thermal insulation } & \multicolumn{2}{|c|}{ Without vapour barrier } & \multicolumn{4}{|c|}{ With vapour barrier } \\
\hline & Type & $\mathrm{e}_{\mathrm{opt}}$ & $\mathrm{Q}$ & $\mathrm{V}$ & Cond. & Type & $\mathrm{e}[\mathrm{m}]$ & $\mathrm{Q}$ & $\mathrm{V}$ \\
\hline & ERP & 19.9 & 6.4 & 26994 & 1840 & BT & 1136 & 6.3 & 3162 \\
\hline & & & & & & $\mathrm{AF}$ & 46 & 6.3 & 3128 \\
\hline & & & & & & Poly & 228 & 6.3 & 3152 \\
\hline & PLE & 21.0 & 7.0 & 20816 & 1917 & BT & 1037 & 6.9 & 3300 \\
\hline \multirow[t]{9}{*}{-10} & & & & & & $\mathrm{AF}$ & 42 & 6.9 & 3265 \\
\hline & & & & & & Poly & 208 & 6.9 & 3292 \\
\hline & CRT & 22.3 & 8.7 & 24267 & 1825 & BT & 932 & 8.6 & 3696 \\
\hline & & & & & & $\mathrm{AF}$ & 38 & 8.6 & 3637 \\
\hline & & & & & & Poly & 187 & 8.6 & 3686 \\
\hline & ERP & 25.5 & 6.2 & 27667 & 2060 & $\mathrm{BT}$ & 3248 & 6.1 & 1285 \\
\hline & & & & & & $\mathrm{AF}$ & 130 & 6.1 & 1285 \\
\hline & & & & & & Poly & 650 & 6.1 & 1284 \\
\hline & PLE & 26.9 & 6.8 & 20280 & 2095 & BT & 3042 & 6.7 & 1343 \\
\hline \multirow[t]{9}{*}{-20} & & & & & & $\mathrm{AF}$ & 122 & 6.7 & 1340 \\
\hline & & & & & & Poly & 608 & 6.7 & 1344 \\
\hline & CRT & 28.7 & 8.5 & 24307 & 2056 & BT & 2711 & 8.4 & 1514 \\
\hline & & & & & & $\mathrm{AF}$ & 109 & 8.4 & 1506 \\
\hline & & & & & & Poly & 542 & 8.4 & 1514 \\
\hline & ERP & 31.2 & 6.0 & 27209 & 2148 & $\mathrm{BT}$ & 9115 & 6.0 & 485 \\
\hline & & & & & & $\mathrm{AF}$ & 364 & 6.0 & 486 \\
\hline & & & & & & Poly & 1820 & 6.0 & 486 \\
\hline & PLE & 33.0 & 6.6 & 19056 & 2163 & $\mathrm{BT}$ & 8628 & 6.5 & 508 \\
\hline \multirow[t]{5}{*}{-30} & & & & & & $\mathrm{AF}$ & 345 & 6.5 & 508 \\
\hline & & & & & & Poly & 1723 & 6.5 & 509 \\
\hline & CRT & 35.3 & 8.3 & 23404 & 2148 & BT & 7625 & 8.2 & 576 \\
\hline & & & & & & $\mathrm{AF}$ & 305 & 8.2 & 576 \\
\hline & & & & & & Poly & 1522 & 8.2 & 577 \\
\hline
\end{tabular}

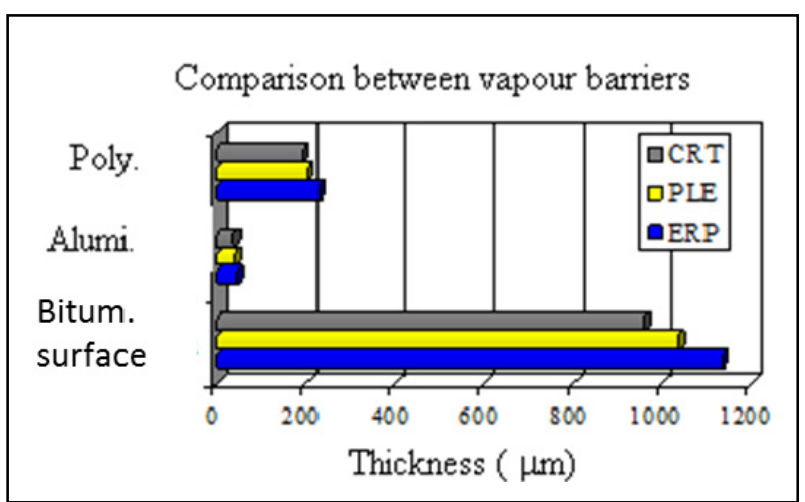

Fig. 7 Simulation results of e three types of vapour barriers $\left(T_{i n t}=-10^{\circ} \mathrm{C}\right)$.
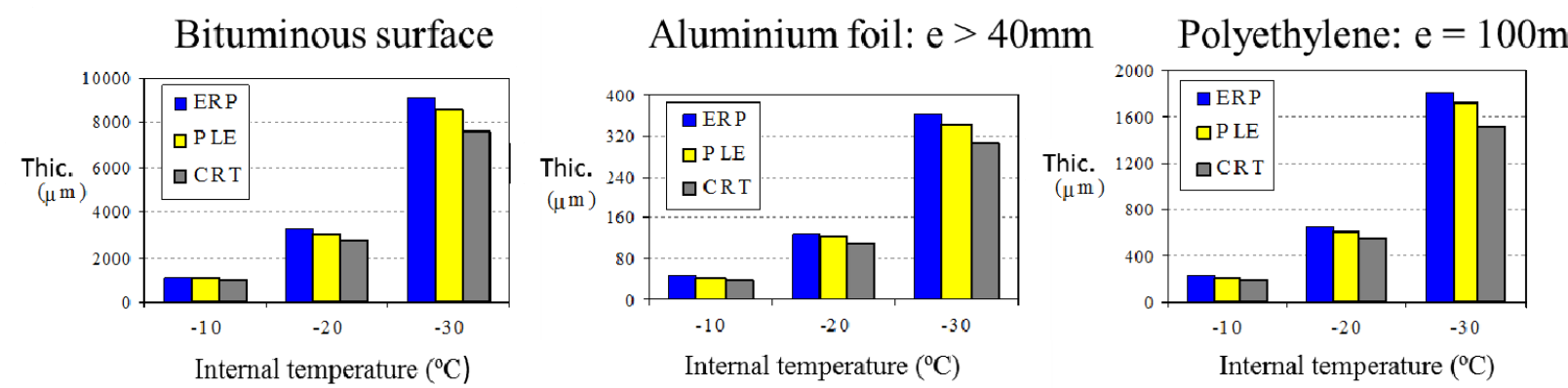

Fig. 8 Variation of the vapor barrier thickness as a function of the type of insulation and internal temperature. 


\section{Conclusions}

The herein performed analysis shows that:

Only in a thermal insulation with minimized thickness, it is impossible to prevent condensation within the cold room envelope. Only with a non-technically feasible thickness would it be possible to avoid it.

Vapour barriers are mandatory, and the procedure for its design was outlined in the previous sections.

The required thickness of the vapor barrier is relatively small, and the most appropriate isolation (maintaining the optimal thickness) is the black cork agglomerate. However, one must note that in order to draw a definitive conclusion, an economic analysis is needed which is not within the scope of this work.

\section{References}

[1] International Institute of Refrigeration. 2015. The Role of
Refrigeration in the Global Economy. Presented at 29th International Institute of Refrigeration (IIR) Paris-France.

[2] Afonso, C. 2013 Sistemas Frigorificos (in English, Refrigeration Systems). Porto, AEFEUP.

[3] Incropera, F. P., and Dewitt, D. P. 1990. "Fundamentos de Transferência de Calor e de Massa (in English, Fundamental of Heat and Mass Transfer.)" Rio de Janeiro:-LTC-Livros Técnicos e Científicos Editora S. A..

[4] Çengel, Y. A. and Boles, M. A. 1994. "Thermodynamics an Engineering Approach.” Sea 1000:8862.

[5] Eckert, E. R. G. and Drake Jr., R. M. 1992. Analysis of Heat and Mass Transfer. NewYork: McGraw-Hill Book Company, U.S.A..

[6] Çengel, Y. A. 1998. Heat Transfer: A Practical Approach. New York: McGraw-Hill Company.

[7] Çengel, Y. A. and Turner, R. H. 2001. Fundamentals of Thermal-Fluid. New York. McGraw-Hill Company.

[8] Dincer, I. and Kanoglu, M. 1994. Refrigeration: Systems and Applications. Georgia: J. Wiley \& Sons.

[9] ASHRAE. 1997. Handbook of Fundamentals. Georgia: Mar Lin Book Company. 